\title{
Visioneering: an essential framework in sustainability science
}

\author{
Joon Kim • Taikan Oki
}

Received: 11 August 2010/Accepted: 22 February 2011/Published online: 26 March 2011

(C) Integrated Research System for Sustainability Science, United Nations University, and Springer 2011

\begin{abstract}
The science of sustainability has inevitably emerged as a vibrant field of research and education that transcends disciplinary boundaries and focuses increasingly on understanding the dynamics of social-ecological systems (SES). Yet, sustainability remains an elusive concept, and its nature seems unclear for the most part. In order to truly mobilize people and nations towards sustainability, we place emphasis on the necessity of understanding the nature, cost and principles of 'visioneering'the engineering of a clear vision. In SES, purpose is the most important pillar, which gives birth to vision-the key to fulfilling the systems' mission. Such a systems perspective leads us to redefine resilience as jumping back to the original purpose, for which SES do not necessarily retain the same structures and functioning after disturbances. A sustainable future will require purpose-driven
\end{abstract}

Edited by Kazuyoshi Okazawa, Japan Industrial Waste Technology Center, Japan.

J. Kim $(\bowtie)$

Complex Systems Science Laboratory,

Department of Landscape Architecture and Rural System

Engineering, Seoul National University, Seoul 151-921, Korea

e-mail: joon@snu.ac.kr

J. Kim · T. Oki

Global Center of Excellence for Sustainable Urban

Regeneration, The University of Tokyo, Tokyo 113-8656, Japan

J. Kim

Global Environment Laboratory, Yonsei University,

Seoul 120-749, Korea

T. Oki

Institute of Industrial Science, The University of Tokyo,

Tokyo 153-8505, Japan transformation of society at all scales, guided by the best foresight, with insight based on hindsight that science can provide. Visioneering with resilience-based systems thinking will provide communities with a logical framework for understanding their interconnections and purposes, envisioning a sustainable web of life, and eventually dancing with the systems.

Keywords Resilience - Social-ecological systems . Sustainability science $\cdot$ Systems thinking $\cdot$ Visioneering

\section{Introduction}

Sustainability science is a new paradigm that sets out to break down the barriers that divide the traditional sciences. It involves not only the integration of disciplines, but also different worldviews and knowledge in the processes of deliberation and assessment (Kemp and Martens 2007). Recently, based on a comprehensive analysis of selected core journals of sustainability science, up to date achievement, research core and framework for sustainability science have been reviewed (Kajikawa 2008). In this process, the studies were classified into three categories: (1) sustainability and its definition, (2) domain-oriented research, and (3) a research framework for sustainability science. In this paper, we focus on the first and third categories.

Kajikawa's review (2008) summarized that the essence of the proposed research framework includes goal setting, indicator setting, indicator measurement, causal chain analysis, forecasting, backcasting, and problem-solution chain analysis. These can be condensed into governance, management, and monitoring (Fig. 1). Here, governance stands as the process of providing a vision and resolving 


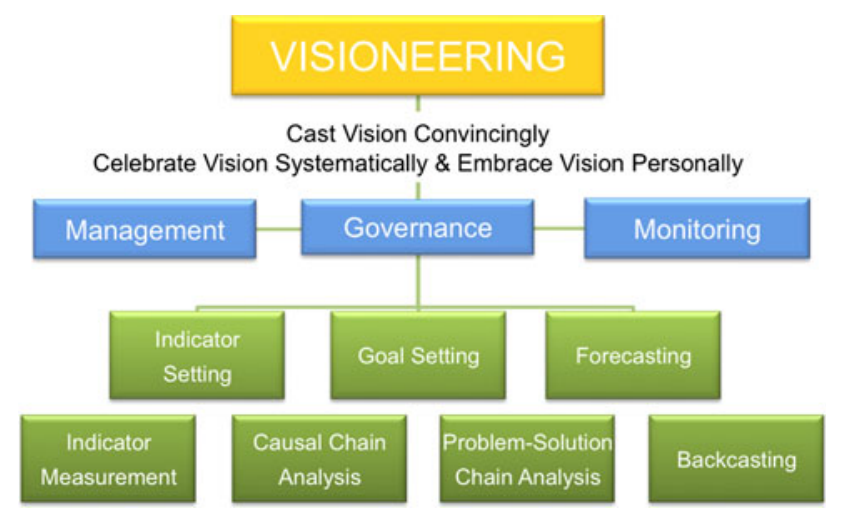

Fig. 1 Visioneering (i.e., the engineering of a clear vision) is the cooperative triad of governance, management, and monitoring, which is an essential framework in the science of sustainability

trade-offs. Management entails operationalizing this vision. Monitoring synthesizes the observations to a narrative and provides feedback, which serves as the source of learning toward sustainability (e.g., Hahn et al. 2008).

Visioneering, then, stands as the cooperative triad of governance, management, and monitoring. It may sound like a new word but is an old concept and a familiar process, i.e., the engineering of a clear vision (Senge 1990; Stanley 1999). The word vision derives from the Latin videre meaning "to see, to discern and to focus." Engineering, on the other hand, is skillful direction and creative application of experiences and scientific principles to develop processes, structures, or equipment. Consequently, visioneering requires the synergy of inspiration, conviction, action, determination, and completion (Stanley 1999).

According to Costanza (2003), visioneering for problem solving in social-ecological systems (SES) requires the integration of three processes: (1) vehement envisioning of how the world works and how we want it to be, (2) systematic analysis conforming to the vision, and (3) implementation appropriate to the vision. He stressed that scientists focus mostly on the second of these steps. Many scientists in this age, particularly emerging ones, carry out research toward scientific goals and objectives but without a shared vision (e.g., Meadows et al. 2004). Embracing a shared vision of a sustainable world enables us to go beyond pursuing individual success to achieving purposes and visions of communal significance.

The purpose of this note and comment is to help awaken the sleeping giants in our communities to envision a sustainable world and to fulfill it. Our objective is to reemphasize the significance of a clear vision and its engineering in sustainability science to move scientists and practitioners towards sustainability.

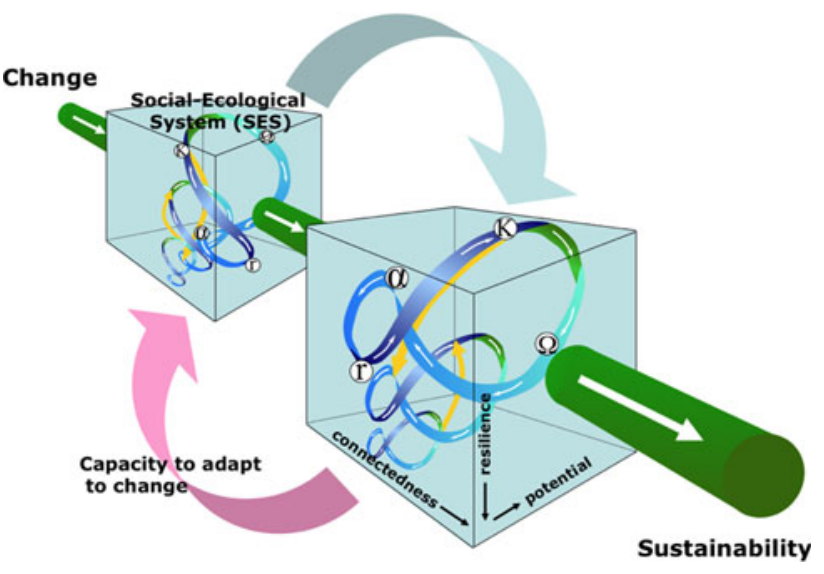

Fig. 2 Envisioning a sustainable future. Sustainability is a dynamic process that requires adaptive capacity in resilient social-ecological systems (SES) to deal with change. At all scales, SES move through their own adaptive cycles consisting of four phases: rapid growth $(r)$, conservation $(K)$, release $(\Omega)$, and reorganization $(\alpha)$. These adaptive cycles are pictured in three-dimensions: (1) potential (or capital); (2) inter-connectedness; and (3) resilience (i.e., the capacity of SES to absorb disturbance while retaining their original purpose). Upper blue arrow Transformation of SES with change, bottom arrow resilience of SESs to go back (adapted from Gunderson and Holling 2002; Berkes et al. 2003)

\section{Sustainability and its nature}

Sustainability remains an elusive concept, and its naturewhat it means, why it matters, who should care, and how it is achieved-is only gradually becoming apparent (e.g., Norberg and Cumming 2008). The definitional expansion has resulted in a diffusion of focus and a vagueness of the direction of sustainability (Kajikawa 2008).

As this new century unfolds, two developments will have major impacts on sustainability: (1) the rise of global capitalism, and (2) the creation of sustainable communities based on biosphere consciousness (Rifkin 2009). Both have to do with networks and innovative technologies, requiring systems thinking - thinking in terms of relationships, context, patterns, processes, and purposes. Inter alia, the following definitions of sustainability, which reflect such a paradigm shift, are worth noting: (1) the use of environment and resources to meet the needs of the present without compromising the ability of future generations to meet their own needs (WCED 1987); (2) a cultural adaptation made by society as it becomes aware of the emerging necessity of non-growth (Daly 1993); (3) a process that is farseeing enough, flexible enough, and wise enough not to undermine the SES of support (Meadows et al. 2004); and (4) the possibility that human and other life will flourish on the Earth forever (Ehrenfeld 2008).

The above definitions make clear that sustainability is not an end product but a dynamic process that requires building resilience and an ability to manage it wisely in 
SES to cope with changes (e.g. Berkes et al. 2003; Loorbach 2007). The resilience approach focuses on the dynamic interplay between periods of gradual and sudden changes, and how to adapt to and shape change (e.g., Holling et al. 2002; Chapin et al. 2009). The word resilience derives from the Latin re- "back" and salire "to jump." Hence, in the teleological systems perspective described below, resilience is redefined simply as jumping back to the original purpose, for which SES do not necessarily retain the same structures and functioning after disturbances. The key to sustainability lies not in optimizing isolated components to be more productive or in maintaining the status quo, but in enhancing the resilience of whole systems through visioneering.

\section{Thinking in systems}

Despite the persistent alarm sound and call to action for almost four decades such as in Limits to Growth (Meadows et al. 2004), the global trajectory is seen to be unsustainable and SES continue to deteriorate (e.g., Anthes 1993; Rockström et al. 2009). The major causes of the sustainability paradox can be condensed into the lack of three basics: understanding of the behavior of complex systems, sufficient capacity to perform the actions and changes needed, and political willingness to implement changes (Gallopin 2002). To overcome these obstacles poses new challenges to the ways we (1) characterize a system (e.g., defining the key subsystems and identifying the main issues, values, and potential shocks), (2) assess the resilience of a system, and (3) mobilize scientists and practitioners working together with the public to produce contextualized knowledge (Resilience Alliance 2007).

A system is more than the sum of its parts, and can be defined as an interconnected set of elements that is coherently organized in a way that achieves something (Meadows 2008). In other words, a system must consist of three pillars: elements, interconnections, and purpose (or function for non-human systems). Scientists' attentions have been shifting gradually from studying the elements themselves to their interconnections and feedback mechanisms, and now more toward their purposeful functions and process networks in a whole system (Capra 2002; Mitchell 2009). The least obvious part of the system, i.e., its purpose, deserves more attention because it gives birth to a vision and is often the most crucial determinant of a system's behavior. Without visioneering, however, the purposes of subunits may add up to an overall behavior that devastates the whole system. Hardin's (1969) The tragedy of the commons is a good example.

In systems thinking, sustainability is a dynamic process, featuring the networks of relationships among the purposeful motions toward a shared vision, the properties of complex SES (i.e., complex collective behavior, sophisticated information processing and adaptation), and the forces acting on them (e.g., change, disturbance) (Fig. 2). In SES, systems lie within systems. At each scale, biological, ecological, and social systems move through their own adaptive cycles (Holling and Gunderson 2002). Sustainability is maintained by relationships among nested sets of these adaptive cycles arranged as a dynamic network and/or hierarchy in space and time (Holling et al. 2002). The linkages across scales play a major role in determining how systems at other scales behave through the networks of processes (e.g., Barabási 2002, Mitchell 2009). Purposes within purposes persist, and thus the harmony of sub-purposes and overall system purposes through visioneering subsists as the essence of sustainable SES. The systems thinking further reminds us that such a hierarchy exists to serve the bottom layers, not the top (Meadows 2008).

\section{Visioneering with systems thinking}

Human lives and communities also go through recurring adaptive cycles as a crucial part of SES. Again, four phases must come to pass (Munroe 2003). The first phase is birth and dependence, in which we rely on the help of others for survival. Here, we are taught and trained regarding what is right and important in life. Second comes the season of independence to discern the purpose of life and to capture the vision. We must listen to our hearts, feel the rhythm of our community, and experience trial and error to draw out purposes from our inner being. During the third phase of interdependence, we turn vision into action, share it with others, and pass it on to the next generation. The final phase is death and a new beginning, in which our lives become the nourishment for the dreams of the next generation who will prosper on the fruit of our vision. And the legacy continues as they carry on our vision, which is further refined with the expanded boundaries of caring others. This analogy of adaptive cycles may provide a scale-free framework that would link natural ecosystems and human social systems (e.g., Capra 2002; Barabási 2002).

In the midst of our torn world, a shared vision stands as the gateway to a community's sustainable future. Etymologically, the word community is defined as groups of people who welcome, honor and exchange one another's gifts (Maser 1999). These days, however, most people live in a world of mediocrity marked by indifference, indecision, status quo, and a lack of vision. A breakthrough on the mediocrity barrier would mean mentally visualizing ourselves on a higher ground-seeing above and beyond the majority. Once we see it, we begin to believe it, and the 
vibrant picture of what could be makes what is no longer tolerable. Vision replaces mental resistance. It begins as a concern and forms in the hearts of those who are inspired with the anticipation between what is and what could be. Further, a compelling reason behind what could be engages those hearts to believe that it should be, bringing forth commitments (Stanley 1999). Vision is the magnet for commitment, the key to unity, and the determinant of destiny.

Despite the plethora of innovative research frameworks and remarkable accomplishments (Kajikawa 2008), the engineering of a lucid vision is still a missing framework in the science of sustainability. Kronenberger points out, "The trouble with our age is all signposts and no destination" (Maser 2008). A sustainable future will require a purpose-driven transformation of society at all scales, guided by the best foresight, with insight based on hindsight that science can provide (i.e., visioneering).

It should be noted that vision is different from goal and objective. Vision is the documented purpose that is detailed, customized, unique, and reasonable (Munroe 2003). A goal is a general statement of intent that remains until it is achieved or no longer needed as the direction changes (Maser 1999). An objective, on the other hand, is a specific and product-oriented statement of intended accomplishment that is attainable, observable, and measurable by specifying no more than what, where, when and how. In contrast to objective, vision focuses on why. Therefore, vision does not change but becomes refined, whereas plans or strategies to achieve it (e.g., goals, objectives) remain flexible and changeable.

Vision must be communicated as shared ownership, which must be both personal and communal (Maser 1999; Meadows 1996; Senge 1990). If followers do not grasp the vision, it is because leaders have not delivered it. In order to fulfill sustainability - the possibility and the destiny that human and nature will prosper together forever, we must make our vision stick, and that is the responsibility of leaders. Stanley (2007) suggests three ways to make vision stick: (1) cast vision strategically (i.e., to define our vision clearly and communicate it as a solution to a problem that must be addressed immediately), (2) celebrate vision systematically (i.e., to rejoice regularly in successes because vision requires constant management and monitoring), and (3) embrace vision personally (i.e., to put our vision into practice in our own life).

Visioneering is easier said than done. It should be, but will not be, without someone's tenacious determination not only to see it through but also to live it through to the end. Life is brutal on vision. That is, as leaders we must first live the vision continuously in our own lives. Only then will we have something to celebrate and rejoice with followers in the successes. Then, we should be able to recast the vision more convincingly, and there will be more celebrations of success, not only of leaders but also of followers. Eventually, the vision sticks to come true as the whole community starts living the shared vision.

\section{Concluding remarks}

Visioneering (i.e., the engineering of a clear vision) is different from visioning (i.e., imagining). Envisioning a sustainable world is an important first step toward sustainability. Without engineering it, however, the vision will not stick and just visioning a sustainable future will remain as a daydream.

Visioneering, by nature, never maintains the status quo and always demands change. Ironically, science itself has become a rigid paradigm in need of shift and is currently going through a painstaking evolution (e.g., Kuhn 1962; Levin and Clark 2010; Wagener et al. 2010). As science enters the agora, the self-organizing capacity of all participants is challenged to be enhanced (Nowotny et al. 2001).

The engineering of vision-the cooperative triad of governance, management, and monitoring-calls for diverse functional groups in our communities to join the processes of collaborative learning and action with stewardship. Such critical functional groups include knowledge carriers, sense makers, networkers, visionaries, leaders, experimenters, entrepreneurs, reinforcers, and followers (Berkes et al. 2003). After all, we are all followers of our predecessors and it is reassuring to witness those informed stewards, who not only know where they are going but also invite us to journey together. Those predecessors, who used to dance with nature, wisely remind us all of the awakening spirit of visioneering: "We do not inherit the Earth from our ancestors, we borrow it from our children."

Acknowledgments This research was supported by grants from Global Center of Excellence program of Japan Society for the Promotion of Science entitled "Global Center for Sustainable Urban Regeneration" and Sustainable Water Resources Center of 21st Century Frontier Research Program (Code: 1-8-3) of Korea, and partially by JSPS KAKENHI, Grants-in-Aid for Scientific Research (S) (19106008). Our thanks go out to Profs. Yozo Fujino, Murugesu Sivapalan and Tony Beckham, Richard Briggs, Phillip Kim and Jessica Min for their inspiration and support; Minseok Kang for preparing the figures; and anonymous reviewers and editor for their thought-provoking comments and suggestions.

\section{References}

Anthes RA (1993) The global trajectory. Bull Am Meteorol Soc 74(6):1121-1130

Barabási AL (2002) Linked: the new science of networks. Cambridge University Press, Perseus 
Berkes F, Colding J, Folke C (2003) Navigating social-ecological systems: building resilience for complexity and change. Cambridge University Press, Cambridge

Capra F (2002) The hidden connections: a science for sustainable living. Anchor Books, New York

Chapin FS III, Kofinas GP, Folke C (2009) Principles of ecosystem stewardship: resilience-based natural resource management in a changing world. Springer, Berlin

Costanza R (2003) A vision of the future science: reintegrating the study of human and the rest of nature. Futures 35:651-671

Daly HE (1993) Sustainable growth: an impossible theorem. In: Daly HE, Townsend KE (eds) Valuing the Earth: economics, ecology, ethics. MIT Press, Cambridge, pp 267-273

Ehrenfeld J (2008) Sustainability by design: a subversive strategy for transforming our consumer culture. Yale University Press, New Haven

Gallopin GC (2002) Planning for resilience: Scenarios, surprises, and branch points. In: Gunderson LH, Holling CS (eds) Panarchy: understanding transformations in human and natural systems. Island, Washington, DC, pp 63-102

Gunderson LH, Holling CS (2002) Panarchy: understanding transformations in human and natural systems. Island, Washington, DC

Hahn T, Schultz L, Folke C, Olsson P (2008) Social networks as sources of resilience in social-ecological systems. In: Norberg J, Cumming GS (eds) Complexity theory for a sustainable future. Columbia University Press, New York, pp 119-148

Hardin G (1969) The tragedy of the commons. Science. 162:1243-1248

Holling CS, Gunderson LH (2002) Resilience and adaptive cycles. In: Gunderson LH, Holling CS (eds) Panarchy: understanding transformations in human and natural systems. Island, Washington, DC, pp 25-62

Holling CS, Gunderson LH, Peterson GD (2002) Sustainability and panarchies. In: Gunderson LH, Holling CS (eds) Panarchy: understanding transformations in human and natural systems. Island, Washington, DC, pp 63-102

Kajikawa Y (2008) Research core and framework of sustainability science. Sustain Sci 3:215-239

Kemp R, Martens P (2007) Sustainable development: how to manage something that is subjective and never can be achieved? Sustain Sci Pract Policy 3(2):5-14. http://ejournal.nbii.org/volume3/ issue 2/

Kuhn TS (1962) The structure of scientific revolutions. The University of Chicago Press, Chicago
Levin SA, Clark WC (2010) Toward a science of sustainability, CID working paper No. 196. Center for International Development, Harvard University, Cambridge, MA

Loorbach D (2007) Governance for sustainability. Sustain Sci Pract Policy 3(2). [online] URL http://ejournal.nbii.org/volume3/ issue $2 /$

Maser C (1999) Vision and leadership in sustainable development. CRC, West Palm Beach

Maser C (2008) Understanding sustainable development. Earthscan, London

Meadows D (1996) Envisioning a sustainable world. In: Costanza R, Segura O, Martinez-Alier J (eds) Getting down to Earth: practical applications of ecological economics. Island, Washington, DC, pp 117-126

Meadows D (2008) Thinking in systems: a primer. Chelsea Green, Vermont

Meadows D, Randers J, Meadows D (2004) Limits to growth: the 30-year update. Chelsea Green, White River Junction, VT

Mitchell M (2009) Complexity: a guided tour. Oxford University Press, New York

Munroe M (2003) The principles and power of vision: keys to achieving personal and corporate destiny. Whitaker House, New Kensington

Norberg J, Cumming GS (2008) Complexity theory for a sustainable future. Columbia University Press, New York

Nowotny H, Scott P, Gibbons M (2001) Re-thinking science: knowledge and the public in an age of uncertainty. Polity, Cambridge, UK

Resilience Alliance (2007) Assessing resilience in social-ecological systems: a scientists workbook. http://www.resalliance.org/ 3871.php

Rifkin J (2009) The empathic civilization: the race to global consciousness in a world in crisis. Tarcher/Penguin, New York

Rockström J et al (2009) Planetary boundaries: exploring the safe operating space for humanity. Ecol Soc 14:32

Senge PM (1990) The fifth discipline: the art and practice of the learning organization. Doubleday, New York

Stanley A (1999) Visioneering: God's blueprint for developing and maintaining vision. Multnomah, Sisters, OR

Stanley A (2007) Making vision stick. Zondervan, Grand Rapids, MI

Wagener T et al (2010) The future of hydrology: an evolving science for a changing world. Water Resour Res 46:W05301. doi: 10.1029/2009WR008906

World Commission on Environment, Development (WCED) (1987) Our common future. Oxford University Press, New York 